\title{
Does unwanted pregnancy lead to adverse health and healthcare utilization for mother and child? Evidence from low- and middle- income countries
}

\author{
Mohammad Hajizadeh $^{1} \cdot$ Son Nghiem ${ }^{2}$
}

Received: 16 August 2018/Revised: 18 March 2020 / Accepted: 19 March 2020/Published online: 9 April 2020

(C) The Author(s) 2020

\begin{abstract}
Objectives Unwanted pregnancy is an important public health concern in low- and middle-income countries (LMICs). Using a pooled dataset from 48 Demographic Health Surveys conducted in Africa, Asia, Latin America and Europe ( $n=494,778)$, we examined the effect of unwanted pregnancy on maternal and child healthcare utilization and child health outcomes in LMICs.

Methods We used logistic regression models to estimate the effect of unwanted pregnancy on antenatal care use, supervised delivery, childhood vaccination and three indicators of child health, viz. stunting (height-for-age), underweight (weight-for-age) and wasting (weight-for-height).

Results We found that mothers of children whose pregnancies had been unwanted had a lower probability of attending four or more antenatal care visits by $3.6 \%$ (95\% confidence interval $=1.9-5.4 \%)$ compared to those whose pregnancy was wanted. We did not find significant impacts of unwanted pregnancy on supervised delivery, childhood vaccination uptake or child health indicators.

Conclusions Birth characteristics, household-level determinants and country-level characteristics seem to be more closely related to maternal and child healthcare utilization as well as child health outcomes than whether the pregnancy was wanted or unwanted in LMICs.
\end{abstract}

Keywords Unwanted pregnancy · Maternal and child healthcare $\cdot$ Child health $\cdot$ Low- and middle-income countries

This article is part of the special issue "Sexual and reproductive health of young people - Focus Africa". The Rudolf Geigy Foundation (Basel, Switzerland) funded the open access publication of this article.

\section{Electronic supplementary material The online version of this} article (https://doi.org/10.1007/s00038-020-01358-7) contains supplementary material, which is available to authorized users.

Mohammad Hajizadeh

m.hajizadeh@dal.ca

1 School of Health Administration, Faculty of Health, Dalhousie University, Sir Charles Tupper Medical Building, 5850 College Street, 2nd Floor, Halifax, NS B3H 4R2, Canada

2 The Centre for Applied Health Economics, Griffith University, Brisbane, Australia

\section{Introduction}

Globally, there are about 210 million pregnancies each year (World Health Organization 2012). Approximately 40\% of these pregnancies are unintended (including mistimed or unwanted at the time of conception), and of these, $50 \%$ are aborted, $13 \%$ are miscarried and $38 \%$ are carried to term (Sedgh et al. 2014). The proportion of unintended pregnancy was found to be specifically higher among younger women (aged 15-19 years old) compared to older women (Ikamari et al. 2013). A pregnancy can be unintended for many reasons such as believing to have too many children already, no desire to have children at the moment, not having the financial resources available to support a new child, being in school, being unmarried, or the pregnancy might have been a result of incorrectly using or lack of access to contraceptives (Singh et al. 2006; Haffejee et al. 2018).

Unintended pregnancies can have significant health, social and economic impacts on the mother and her family 
(Singh et al. 2010). These can include negative effects on the physical and mental health of mothers as well as their quality of life (Schwarz et al. 2008; Khajehpour et al. 2013). In many low- and middle-income countries (LMICs), obtaining an abortion can be illegal or inaccessible, leading to many unsafe abortions either self-induced or performed by untrained professionals (Singh et al. 2018). Regardless of the method, abortions increase costs to the healthcare system and society through the costs associated with performing the abortion and treating complications as a result of a self-induced or unsafe abortion (Sonfield and Kost 2015). The health and social consequences of unintended pregnancies are significant in LMICs, where the majority of unintended pregnancies occur (Gipson et al. 2008).

If the woman cannot obtain an abortion, the unintended pregnancy can impact on her attitude and behaviour during pregnancy and her relationship with her child after it is born. It has been shown that unintended pregnancies are associated with delayed initiation of antenatal care, higher rates of maternal, neonatal and infant mortality and child nutrition status (Rahman 2015; Yazdkhasti et al. 2015). Long-term consequences for the unintended child include increased risk of cognitive impairment and chronic disease, reduced stature (Hoddinott et al. 2013) and an increased likelihood of crime in adulthood (Donohue and Levitt 2001).

To date, some studies (e.g. Marston and Cleland 2003; Wado et al. 2013; Rahman 2015; Singh et al. 2015; Rahman et al. 2016; Baschieri et al. 2017; Echaiz et al. 2018) have analysed the effect of unintended pregnancies on health and healthcare utilization in LMICs. However, the findings from these studies have been inconsistent. Two recent systematic reviews (Gipson et al. 2008; Hall et al. 2017) have called for more studies investigating unintended pregnancies in LMICs, given the limited number of studies and mixed results in the existing literature. Thus, using a dataset pooled from 48 Demographic and Health Surveys (DHS) conducted in Africa, Asia, Latin America and Europe linked with country-level indicators from the World Bank's World Development Indicators and Global Development Finance (WDI and GDF) data sets (World Bank 2019), we analysed the impact of unwanted pregnancy on the receipt of antenatal care use, supervised delivery, childhood vaccination and child nutritional status as measured through stunting, underweight and wasting.

\section{Methods}

\section{Data}

The data for the analysis were obtained from DHS (https:// www.dhsprogram.com/) collected from 48 LMICs through the Monitoring and Evaluation to Assess and Use Results the Standard Demographic and Health Surveys (MEASURE DHS) project over the period between 2010 and 2016. The standard DHS surveys are large nationally representative cross-sectional household surveys between 5000 and 30,000 households, typically conducted every 5 years in selected LMICs (The DHS Program 2019). The DHS collects comparable and reliable information on a variety of maternal and child health and healthcare indicators (Rutstein and Rojas 2006) by using a multistage sampling procedure (Demographic and Health Survey 1996). The data were collected using face-to-face interviews by trained interviewers. The DHS surveys use a similar set of questions to increase comparability across time and countries (Demographic and Health Survey 2006). Data collection methods and reliability and validation assessments can be found elsewhere (Rutstein and Rojas 2006). The final sample contained 494,778 singleton live births, aged 1-59 months, from 48 LMICs. Selection of countries was determined by the availability of DHS surveys between 2010 and 2016. In addition, the World Bank's WDI and GDF datasets (World Bank 2019) were used to obtain country-level information. The country-level information was linked to each child included in the DHS surveys using the child's birth year. Table 1 reports survey years, sample size and gross domestic product (GDP) per capita for the sampled countries.

\section{Variables}

\section{Outcome variables}

We examined the effect of unwanted pregnancy carried to term (hereafter 'unwanted pregnancy') on antenatal care use, supervised delivery and childhood vaccination as outcome measures of healthcare utilization during the antenatal/prenatal, intranatal and postpartum/postnatal stages, respectively. In addition, we looked at the effect of unwanted pregnancy on three child health outcome indicators: stunting (height-for-age); underweight (weight-forage); and wasting (weight-for-height). These outcomes were chosen based on previous studies (Marston and Cleland 2003) to reflect the different stages at which an unwanted pregnancy might have an impact on health outcomes.

The 2016 World Health Organization (WHO) guideline of antenatal care (ANC) recommends a minimum of eight contacts to reduce perinatal mortality and improve mother's experience of care. As our analyses used data before the change in the guideline, we used the 2006 WHO recommendation (World Health Organization 2006a) and defined adequate ANC use as a binary variable indicating whether or not the mother attended four or more ANC visits during her pregnancy. Supervised delivery was 
Table 1 Survey year, sample size and gross domestic product per capita for the sampled 48 low- and middle-income countries from Africa, Asia, Latin America and Europe, Demographic Health Surveys, 2010-2016

\begin{tabular}{|c|c|c|c|c|c|}
\hline \multirow[t]{2}{*}{ Country } & \multirow[t]{2}{*}{ Country code } & \multirow[t]{2}{*}{ Survey year } & \multicolumn{2}{|l|}{ Sample size } & \multirow{2}{*}{$\begin{array}{l}\text { Gross domestic } \\
\text { product per capita }\end{array}$} \\
\hline & & & Household & Children 0-59 months & \\
\hline \multicolumn{6}{|l|}{ Low-income countries } \\
\hline Afghanistan & $\mathrm{AF}$ & 2015 & 24,395 & 32,026 & 1808 \\
\hline Bangladesh & $\mathrm{BD}$ & 2014 & 17,300 & 5381 & 2979 \\
\hline Benin & $\mathrm{BJ}$ & 2011-2012 & 17,422 & 12,712 & 1779 \\
\hline Burkina Faso & $\mathrm{BF}$ & 2010 & 14,424 & 14,455 & 1421 \\
\hline Burundi & $\mathrm{BI}$ & 2010 & 8596 & 7558 & 708 \\
\hline Cambodia & $\mathrm{KH}$ & 2014 & 15,825 & 7029 & 3113 \\
\hline Chad & TD & 2014-2015 & 17,233 & 18,024 & 2059 \\
\hline Comoros & KM & 2012 & 4482 & 3000 & 1403 \\
\hline Congo Democratic Republic & $\mathrm{CD}$ & 2013-2014 & 18,171 & 18,010 & 692 \\
\hline Gambia & GM & 2013 & 6217 & 7795 & 1593 \\
\hline Guinea & $\mathrm{GN}$ & 2012 & 7109 & 6720 & 1197 \\
\hline Haiti & HT & 2012 & 13,181 & 7025 & 1585 \\
\hline Liberia & LR & 2013 & 9333 & 7300 & 817 \\
\hline Malawi & MW & 2010 & 24,825 & 19,093 & 1061 \\
\hline Mali & ML & 2012-2013 & 10,105 & 9982 & 1787 \\
\hline Mozambique & $\mathrm{MZ}$ & 2011 & 13,919 & 10,657 & 952 \\
\hline Nepal & NP & 2011 & 10,826 & 5240 & 2042 \\
\hline Niger & $\mathrm{NE}$ & 2012 & 10,750 & 12,125 & 867 \\
\hline Rwanda & RW & 2014-2015 & 12,699 & 7629 & 1620 \\
\hline Sierra Leone & SL & 2013 & 12,629 & 11,411 & 1854 \\
\hline Tajikistan & $\mathrm{TJ}$ & 2012 & 6432 & 4889 & 2343 \\
\hline Tanzania & $\mathrm{TZ}$ & 2015-2016 & 12,563 & 9780 & 2510 \\
\hline Togo & TG & 2013-2014 & 9549 & 6670 & 1316 \\
\hline Uganda & UG & 2011 & 9033 & 7621 & 1665 \\
\hline Zimbabwe & ZW & 2010-2011 & 9756 & 5416 & 1456 \\
\hline \multicolumn{6}{|c|}{ Lower-middle-income countries $^{\mathrm{b}}$} \\
\hline Armenia & $\mathrm{AM}$ & 2010 & 6700 & 1453 & 6508 \\
\hline Cameroon & $\mathrm{CM}$ & 2011 & 14,214 & 11,156 & 2614 \\
\hline Congo Brazzaville & CG & $2011-2012$ & 11,632 & 8927 & 5665 \\
\hline Cote d'Ivoire & $\mathrm{CI}$ & $2011-2012$ & 9686 & 7402 & 2650 \\
\hline Egypt & EG & 2014 & 28,175 & 15,227 & 10,049 \\
\hline Ghana & $\mathrm{GH}$ & 2014 & 11,835 & 5597 & 3894 \\
\hline Honduras & $\mathrm{HN}$ & $2011-2012$ & 21,362 & 10,719 & 4491 \\
\hline Indonesia & ID & 2012 & 43,852 & 17,672 & 9283 \\
\hline Kenya & $\mathrm{KE}$ & 2014 & 36,430 & 9811 & 2819 \\
\hline Kyrgyz Republic & KG & 2012 & 8040 & 4267 & 2870 \\
\hline Lesotho & LS & 2014 & 9402 & 3051 & 2760 \\
\hline Nigeria & NG & 2013 & 38,522 & 30,252 & 5448 \\
\hline Pakistan & PK & 2012-2013 & 12,943 & 11,483 & 4429 \\
\hline Philippines & PH & 2013 & 14,804 & 7099 & 6366 \\
\hline Senegal & $\mathrm{SN}$ & 2014 & 4231 & 13,122 & 2202 \\
\hline Yemen & YE & 2013 & 17,351 & 15,731 & 3879 \\
\hline Zambia & $\mathrm{ZM}$ & 2013-2014 & 15,920 & 13,020 & 3582 \\
\hline \multicolumn{6}{|c|}{ Upper-middle-income countries ${ }^{\mathrm{b}}$} \\
\hline Colombia & $\mathrm{CO}$ & 2010 & 51,447 & 17,487 & 10,901 \\
\hline
\end{tabular}


Table 1 (continued)

\begin{tabular}{|c|c|c|c|c|c|}
\hline \multirow[t]{2}{*}{ Country } & \multirow[t]{2}{*}{ Country code } & \multirow[t]{2}{*}{ Survey year } & \multicolumn{2}{|l|}{ Sample size } & \multirow{2}{*}{$\begin{array}{l}\text { Gross domestic } \\
\text { product per capita }\end{array}$} \\
\hline & & & Household & Children 0-59 months & \\
\hline Dominican Republic & DO & 2013 & 11,464 & 3628 & 11,888 \\
\hline Gabon & GA & 2012 & 9755 & 5787 & 17,595 \\
\hline Jordan & $\mathrm{JO}$ & 2012 & 15,190 & 9993 & 10,243 \\
\hline Namibia & NA & 2013 & 9849 & 4892 & 9140 \\
\hline Peru & $\mathrm{PE}$ & 2012 & 27,218 & 9454 & 10,944 \\
\hline Total & & & 746,796 & 494,778 & \\
\hline
\end{tabular}

${ }^{\mathrm{a}}$ The gross domestic product per capita at purchasing power parity, constant 2011 international \$

bThe 2017 World Bank classification of the world's economies is used to categorize sampled countries into low-income countries, lower-middleincome countries and upper-middle-income countries groups

measured as a binary variable representing whether or not health professionals (e.g. a midwife, doctor or nurse) assisted the delivery, as per the WHO definition (World Health Organization 2004). Childhood vaccination was measured by a binary variable of whether or not the child completed the WHO recommended immunization schedule (see Table A.1 in the Online Resource) for four routine vaccines, viz. Bacillus Calmette-Guérin (BCG), polio (3 doses), diphtheria, tetanus and pertussis (DTP, 3 doses) and measles vaccines (World Health Organization 2019). Children were considered as vaccinated if they were younger than 11 months and completed the WHO recommended immunization schedule or they were 11 months and older and completed all the four routine vaccines.

Three binary variables were used to measure child health outcome. Childhood stunting was defined whether or not the height-for-age $Z$-score (HAZ) of the child was below two standard deviations (HAZ $<-2 \mathrm{SD})$ from the median of the reference population as defined by the WHO growth standards (World Health Organization 2006b). Similarly, childhood wasting and underweight were measured by whether or not the weight-for-height $Z$-score (WHZ) and weight-for-age $Z$-score (WAZ) of the child were below two SD from the median of the reference population as defined by the WHO growth standards, respectively (World Health Organization 2006b). These analyses were restricted to surviving children with HAZ, WHZ and WAZ values between -6 and 6 as $Z$-scores outside this range are biologically implausible values based on WHO definition (De Onis 2006). We generated $Z$-scores for height-for-age, weight-for-height and weight-for-age using the 2006 WHO growth standard (World Health Organization 2006b) and the Stata's user-written programme zscore06 (Leroy 2011).

\section{Exposure variable}

Whether a pregnancy was wanted or not was determined based on the intention status of the pregnancy: wanted then, wanted later, not wanted. The intention status of the pregnancy was collected using the following question in the DHS enquiries: "At the time you became pregnant with (name of child), did you want to become pregnant then, did you want to wait until later, or did you want no more children at all?" (Marston and Cleland 2003). Previous studies have often used wanted/planned, mistimed and unwanted terms, respectively, to represent the intention status of the pregnancies (e.g. Marston and Cleland 2003; D'Angelo et al. 2004). Since mistimed pregnancies are ultimately wanted pregnancies and studies (Marston and Cleland 2003) have documented non-significant or reduced differences between mistimed and wanted pregnancies, in this study, as other studies have previously done (e.g. Barrick and Koenig 2008), we classified mistimed pregnancies as wanted pregnancies.

\section{Control variables}

Based on the extant literature (Marston and Cleland 2003; Hajizadeh et al. 2015; Rahman 2015; Singh et al. 2015; Rahman et al. 2016; Baschieri et al. 2017; Hajizadeh 2019), we controlled for birth characteristics (gender, age of child, birth order) and household-level covariates (mother's age at birth, mother's marital status, mother's education, household living standard/wealth and region) that have been consistently collected in all DHS surveys and country-level covariates [GDP per capita and public health expenditures per capita in purchasing power parity (PPP), 2011 prices, international \$] in our analysis. A constructed wealth index (WI) for each household in the DHS surveys was used as a measure of the household living standard. Using a method suggested by Filmer and Pritchett (2001), the DHS uses information collected on selected household's assets (e.g. bicycles, radio, televisions), types of sanitation facilities, water source and building materials to construct a measure of household living standard, the WI (Rutstein and Johnson 2004). We 
used the WDI and GDF data sets (World Bank 2019) to obtain country-level covariates for each country in our study. To correct for excessive skewness, we used the natural logarithm transformation of GDP per capita and public health expenditures per capita in the analysis. Table 2 reports the definitions and summary statistics of all the variables used in the study.

\section{Statistical analysis}

Since all outcome variables were binary, we used multivariable logistic regressions to examine the extent to which unwanted pregnancy affects ANC, supervised delivery, childhood vaccination and child health outcomes, controlling for exogenous independent variables. A general specification of the multivariable logistic regression is:

$\log i t\left[\pi\left(y_{i t}\right)\right]=\beta+\gamma x_{i t}+\alpha_{i}+\varepsilon_{i t}$,

where $\left(y_{i t}\right)=\frac{p(y)}{1+p(y)}$, which transforms the probability of outcome $y$ (e.g. stunting, wasting and childhood vaccination) of country $i$ in a period $t, p(y)$, from $(0,1)$ to $(-\propto$, $+\propto$ ), allowing a standard linear regression to be applied. $x$ are the set of independent variables [e.g. age, sex and socio-economic status (SES)] affecting the probability that outcome $y$ will occur, $\alpha$ represents country dummies (or fixed effects), and $\varepsilon$ is the random noise. We included county fixed effects to account for unobserved heterogeneity between countries (e.g. cultural differences) that effects our outcome variables. The parameters of interest $(\gamma)$ are difficult to interpret directly. Thus, we calculated marginal effects at the means of the independent variables to report the effect of each explanatory variable on the probability of the outcome variables. Based on the annual female population provided by the Population Division of the United Nations (UN DESA 2020), we applied the denormalization of standard weights approach, as per the DHS Sampling and Household Listing Manual (ICF International 2012), to calculate an appropriate weight for each observation in the analyses. We calculated 95\% confidence intervals $(\mathrm{CI})$ for the marginal effects, taking into account the effect of the geographical clustering of the sample. All analyses were performed with Stata software package (version 15, StataCorp, College Station, Tex).

\section{Results}

\section{Unwanted pregnancy in LMICs}

Table A.2 in the Online Resource shows the proportion of pregnancies (\%) reported as unwanted in the 48 LMICs by sex and region. The overall prevalence of unwanted pregnancies was $9 \%$ in the sampled countries. The proportion of pregnancies reported as unwanted in the 48 LMICs varied from less than $1 \%$ in the Kyrgyz Republic to about $30 \%$ in Malawi (see Table A.2 in the Online Resource and Fig. 1). The proportion of unwanted pregnancies for male and female was $8.54 \%$ and $8.58 \%$, respectively. The proportion of unwanted pregnancies was $9.27 \%$ in rural areas, whereas this figure was $8.21 \%$ in urban areas.

Figure 2 shows the cross-country correlation between the proportion of unwanted pregnancies and log GDP per capita. There was a positive but weak association (beta = 2.4, $p$ value $=0.07$ ) between the log of GDP per capita and the $\log$ of the proportion of unwanted pregnancies across countries: a $1 \%$ increase in GDP per capita was associated with $0.024 \%$ increase in the proportion of unwanted pregnancy.

\section{Unwanted pregnancy and maternal/child healthcare and child health outcomes}

Table 3 provides the results of multivariable logistic regression, showing the relationship between unwanted pregnancy and maternal and child healthcare and child health outcomes in the 48 LMICs after adjusting for the potential confounding factors, including birth characteristics and household-level covariates, country-level covariates and county fixed effects. Results indicated that mothers whose pregnancy was unwanted had a lower probability of having adequate ANC by $3.6 \%$ [95\% confidence interval (CI) 1.9-5.4\%] compared to those whose pregnancy was wanted. There were no significant differences in supervised delivery, childhood vaccination and nutritional status (measured by stunting, underweight and wasting) of children born from unwanted and wanted pregnancies.

The results revealed significant effects of birth characteristics, household-level determinants and country-level characteristics on maternal and child healthcare utilization, as well as child health outcomes. In particular, compared with girls, boys were $1 \%$ (95\% CI $0.3-0.5 \%$ ) more likely to receive prenatal care or $1.6 \%$ (95\% CI $0.9-2.3 \%$ ) more likely to receive supervised delivery. The probability of stunting, underweight or wasting in boys was higher than that of girls by $4.4 \%$ (95\% CI 3.6-5.1\%), $2.6 \%$ (95\% CI $2-3.2 \%$ ) and $1 \%$ (95\% CI: 0.6 to $1.5 \%$ ), respectively. Birth order was one of the most influential factors contributing to prenatal care, intranatal care, postnatal care and health outcomes. Compared with children of birth order one (i.e. the first child), children of birth order two and above received lower antenatal care, supervised delivery and childhood vaccination. Mother's age at birth also played a critical role in pregnancy care and child health. Children to mothers who were younger than 20 years old (compared with 20 and 40 years old) at the time of birth had a 
Table 2 Definitions and summary statistics of variables used in the analysis, Demographic Health Surveys from 48 low- and middle-income countries in Africa, Asia, Latin America and Europe, 2010-2016

\begin{tabular}{|c|c|c|c|}
\hline Variable & Definition & Mean & SD \\
\hline \multicolumn{4}{|l|}{ Outcome variables } \\
\hline Antenatal care & $=1$ if mother received four or more antenatal care, 0 otherwise & 0.58 & 0.49 \\
\hline Supervised delivery & $\begin{array}{l}=1 \text { if delivery assisted by a health professional such as a midwife, doctor or nurse. } 0 \\
\text { otherwise }\end{array}$ & 0.52 & 0.50 \\
\hline Child vaccination & $\begin{array}{l}=1 \text { if the child completed the WHO recommended immunization schedule for four routine } \\
\text { vaccines, } 0 \text { otherwise }\end{array}$ & 0.49 & 0.50 \\
\hline Stunting & $\begin{array}{l}=1 \text { if the height-for-age Z-score (HAZ) of the child is below minus two SD from the median } \\
\text { of the reference population, defined by the WHO growth standards, } 0 \text { otherwise }\end{array}$ & 0.33 & 0.47 \\
\hline Underweight & $\begin{array}{l}=1 \text { if the weight-for-height Z-Score (WHZ) of the child is below minus two SD from the } \\
\text { median of the reference population, defined by the WHO growth standards, } 0 \text { otherwise }\end{array}$ & 0.21 & 0.41 \\
\hline Wasting & $\begin{array}{l}=1 \text { if the weight-for-age (WAZ) of the child is below minus two SD from the median of the } \\
\text { reference population, defined by the WHO growth standards, } 0 \text { otherwise }\end{array}$ & 0.11 & 0.31 \\
\hline \multicolumn{4}{|l|}{ Exposure variable } \\
\hline Unwanted pregnancy & $=1$ if the pregnancy is unwanted, 0 otherwise & 0.09 & 0.28 \\
\hline Wanted pregnancy (Ref.) & $=1$ if the pregnancy is wanted, 0 otherwise & 0.91 & 0.28 \\
\hline \multicolumn{4}{|l|}{ Birth characteristics } \\
\hline Male & $=1$ if the child is male, 0 otherwise & 0.51 & 0.50 \\
\hline Female (Ref.) & $=1$ if the child is female, 0 otherwise & 0.49 & 0.50 \\
\hline Age of child (years) & Child's age in years & 2.40 & 1.43 \\
\hline Birth order\# 1 (Ref.) & $=1$ if the birth order of the child is one, 0 otherwise & 0.26 & 0.44 \\
\hline Birth order\# 2 & $=1$ if the birth order of the child is two, 0 otherwise & 0.22 & 0.41 \\
\hline Birth order\# 3 and above & $=1$ if the birth order of the child is three or above, 0 otherwise & 0.51 & 0.50 \\
\hline \multicolumn{4}{|l|}{ Household-level covariates } \\
\hline Mother's age at birth $(<20$ years $)$ & $=1$ if the mother's age at birth is less than 20 years, 0 otherwise & 0.10 & 0.30 \\
\hline $\begin{array}{l}\text { Mother's age at birth } \\
(19<\text { years }<41) \text { (Ref.) }\end{array}$ & $=1$ if the mother's age at birth is between 20 and 40 years, 0 otherwise & 0.85 & 0.36 \\
\hline Mother's age at birth ( $>40$ years) & $=1$ if the mother's age at birth is greater than 40 years, 0 otherwise & 0.05 & 0.21 \\
\hline $\begin{array}{l}\text { Mother's marital status-married } \\
\text { (Ref.) }\end{array}$ & $=1$ if the mother is married, 0 otherwise, 0 otherwise & 0.84 & 0.37 \\
\hline $\begin{array}{l}\text { Mother's marital status—formally } \\
\text { married }\end{array}$ & $=1$ if the mother is formally married, 0 otherwise & 0.16 & 0.37 \\
\hline Mother's education (years) & Mother's education in years & 5.38 & 4.94 \\
\hline $\begin{array}{l}\text { Household socio-economic status, } \\
\text { 1st quintile (Ref.) }\end{array}$ & $1=$ if the socio-economic status of the household is in the first (lowest) quintile, 0 otherwise & 0.20 & 0.40 \\
\hline $\begin{array}{l}\text { Household socio-economic status, } \\
\text { 2nd quintile }\end{array}$ & $1=$ if the socio-economic status of the household is in the second quintile, 0 otherwise & 0.20 & 0.40 \\
\hline $\begin{array}{l}\text { Household socio-economic status, } \\
\text { 3rd quintile }\end{array}$ & $1=$ if the socio-economic status of the household is in the third quintile, 0 otherwise & 0.20 & 0.40 \\
\hline $\begin{array}{l}\text { Household socio-economic status, } \\
\text { 4th quintile }\end{array}$ & $1=$ if the socio-economic status of the household is in the fourth quintile, 0 otherwise & 0.20 & 0.40 \\
\hline $\begin{array}{l}\text { Household socio-economic status, } \\
\text { 5th quintile }\end{array}$ & $1=$ if the socio-economic status of the household is in the fifth (highest) quintile, 0 otherwise & 0.20 & 0.40 \\
\hline Rural & $1=$ if the child resides in a rural area, 0 otherwise & 0.67 & 0.47 \\
\hline Urban (Ref.) & $1=$ if the child resides in an urban area, 0 otherwise & 0.33 & 0.47 \\
\hline \multicolumn{4}{|l|}{ Country-level covariates } \\
\hline $\begin{array}{l}\text { Log gross domestic product per } \\
\text { capita }\end{array}$ & $\begin{array}{l}\text { Natural log of gross domestic product per capita at purchasing power parity, constant } 2011 \\
\text { international \$ }\end{array}$ & 8.11 & 0.79 \\
\hline $\begin{array}{l}\text { Log public health expenditures } \\
\text { per capita }\end{array}$ & $\begin{array}{l}\text { Natural log of public health expenditures per capita at purchasing power parity, constant } \\
2011 \text { international \$ }\end{array}$ & 3.95 & 0.82 \\
\hline
\end{tabular}


Table 2 (continued)

\begin{tabular}{lll}
\hline Variable & Definition & Mean \\
\hline $\begin{array}{l}\text { Country fixed effects covariates } \\
48 \text { dummy variables for countries }\end{array}$ & $\begin{array}{c}=1 \text { if the child was born in the country, 0 otherwise (dummy variable for Nigeria was used } \\
\text { as Ref. ) }\end{array}$ & -
\end{tabular}

We used the de-normalized standard weight (as per the Demographic Health Survey Sampling and Household Listing Manual (ICF International 2012) as a weight to compute summary statistics

$S D$ standard deviation, WHO World Health Organization, Ref. reference category in the regression analyses

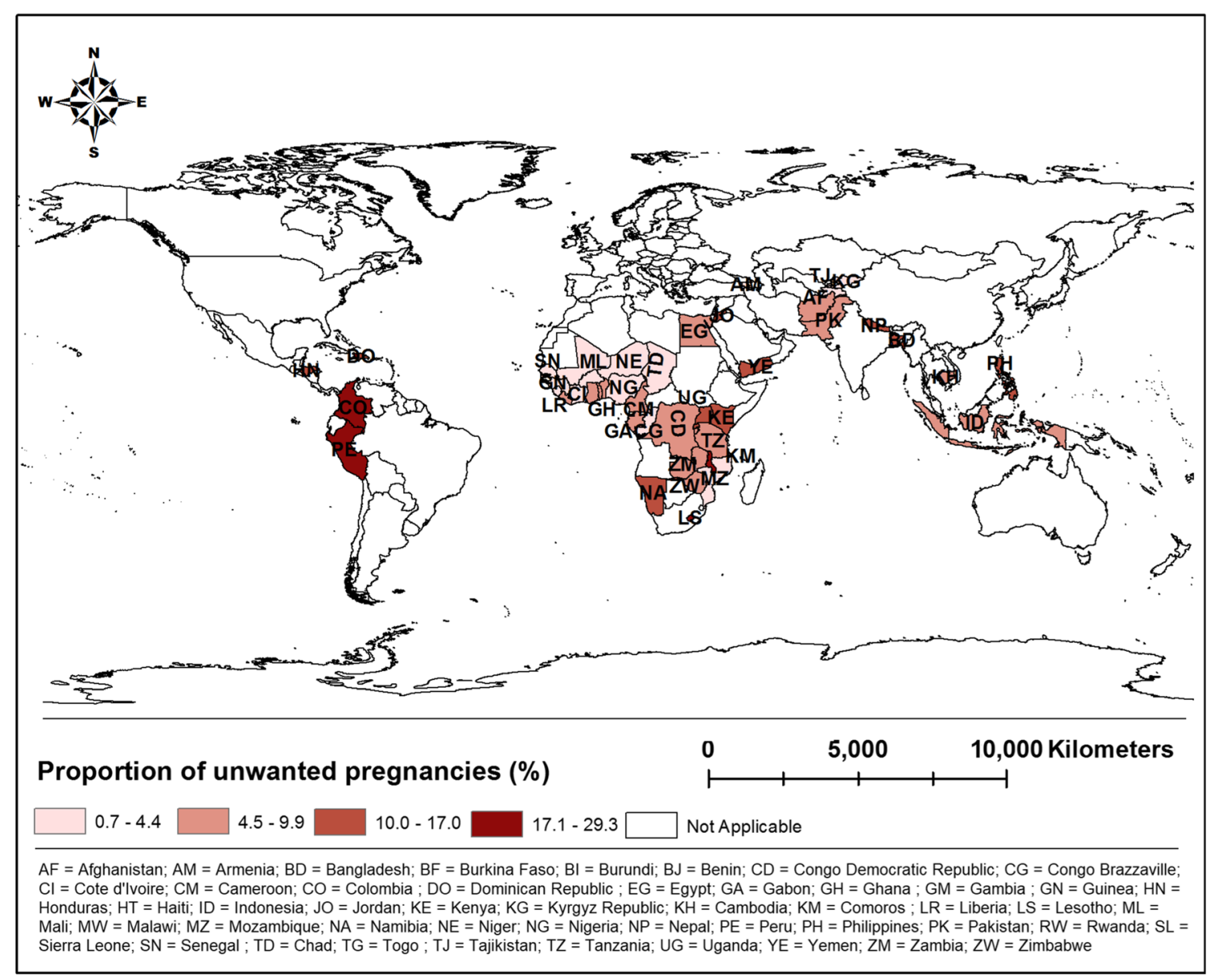

Fig. 1 Proportion of unwanted pregnancies in 48 low- and middle-income countries from Africa, Asia, Latin America and Europe, Demographic Health Surveys, 2010-2016

significantly lower probability of antenatal care, supervised delivery and childhood vaccination, while having a higher probability of stunting and underweight. Mother's education and household SES had significant positive effects on pregnancy care and child health. The positive effects of SES were also present at the country level, where higher GDP per capita and public health expenditure were associated with a reduction in stunting by and underweight among children.

\section{Discussion}

Unwanted pregnancy is an important public health problem in LMICs countries, especially among young women (Singh and Darroch 2000). Notwithstanding the high prevalence of unwanted pregnancies in LMICs, there has been a limited number of studies investigating the relationship between unwanted pregnancies and maternal and child healthcare utilization and child health outcomes. We used a large dataset pooled from 48 Demographic Health 
Fig. 2 Cross-country correlation between the proportion $(\%)$ of unwanted pregnancies and log gross domestic product per capita in 48 low- and middle-income countries from Africa, Asia, Latin America and Europe, Demographic Health Surveys, 2010-2016

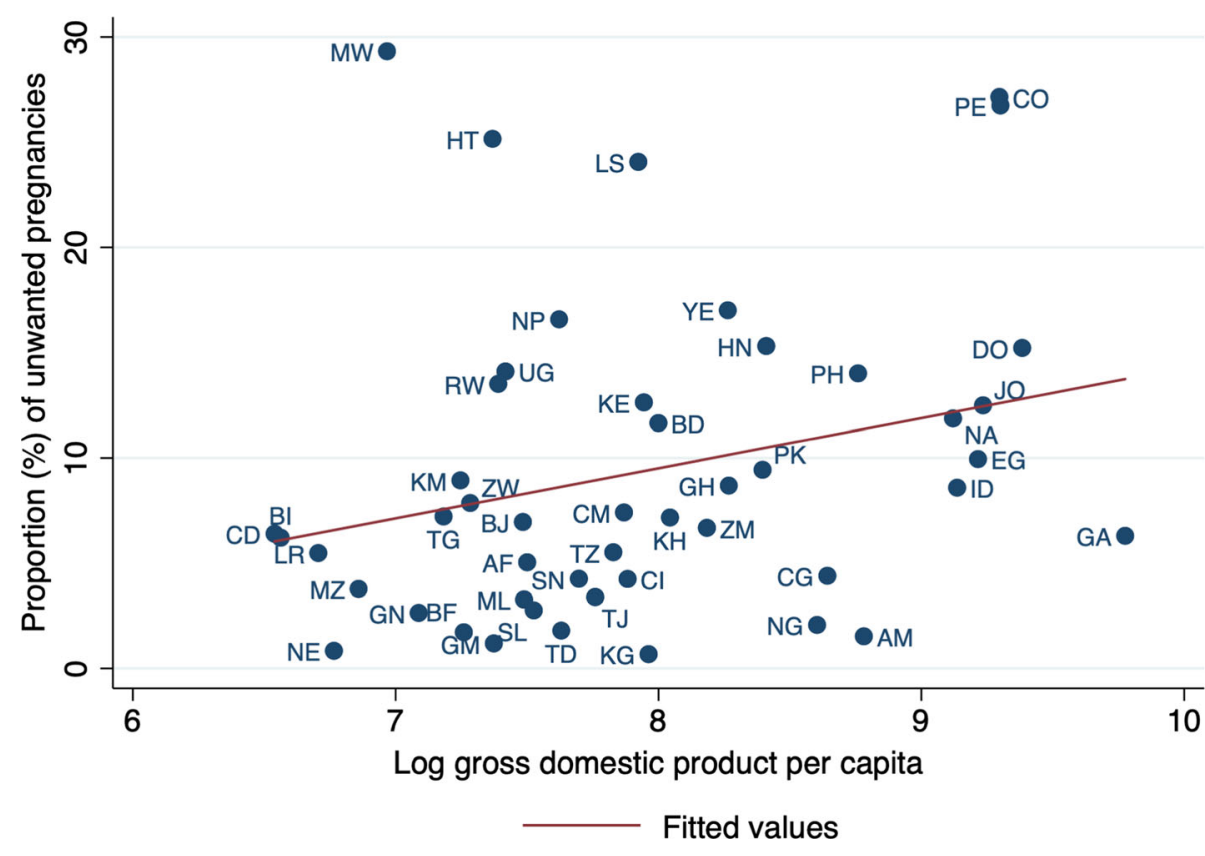

2013). Apart from the attitude towards the unwanted pregnancy of an expecting mother, her financial position may influence the decision to have supervised delivery or not (Rahman et al. 2016). The inconsistency between the results of our study and the findings from Peru (Marston and Cleland 2003) could be due to the difference in the study population and time frame of the studies. Differences in the population and definition of supervised delivery may explain the discrepancy between our result and the result of the previous study from Bangladesh (Rahman et al. 2016).

Despite the potential negative impact of unwanted pregnancies on child health outcomes, thought to be due to conscious or unconscious maternal feelings and behaviours towards the unwanted pregnancy leading to neglect (Singh et al. 2017), we did not find such an effect in this study. Our results did not reveal a significant effect of unwanted pregnancy on childhood vaccination or in child nutritional status measured by stunting, underweight and wasting. In the literature, evidence for the association between unwanted pregnancy and childhood vaccination and child nutritional status has been variable. Studies in Nepal, Kenya and Peru have found unwanted pregnancies to be associated with incomplete vaccination statuses by the child's first birthday (Marston and Cleland 2003; Singh et al. 2015; Echaiz et al. 2018), but no relationship was found in Bolivia and the Philippines (Marston and Cleland 2003). Likewise, for nutritional status, children of unwanted pregnancies in Bangladesh were more likely to be stunted, wasted and underweight (Rahman 2015); however, no effect was found between pregnancy intention and stunting in Malawi (Baschieri et al. 2017). The inconsistency between our results and the previous findings could 


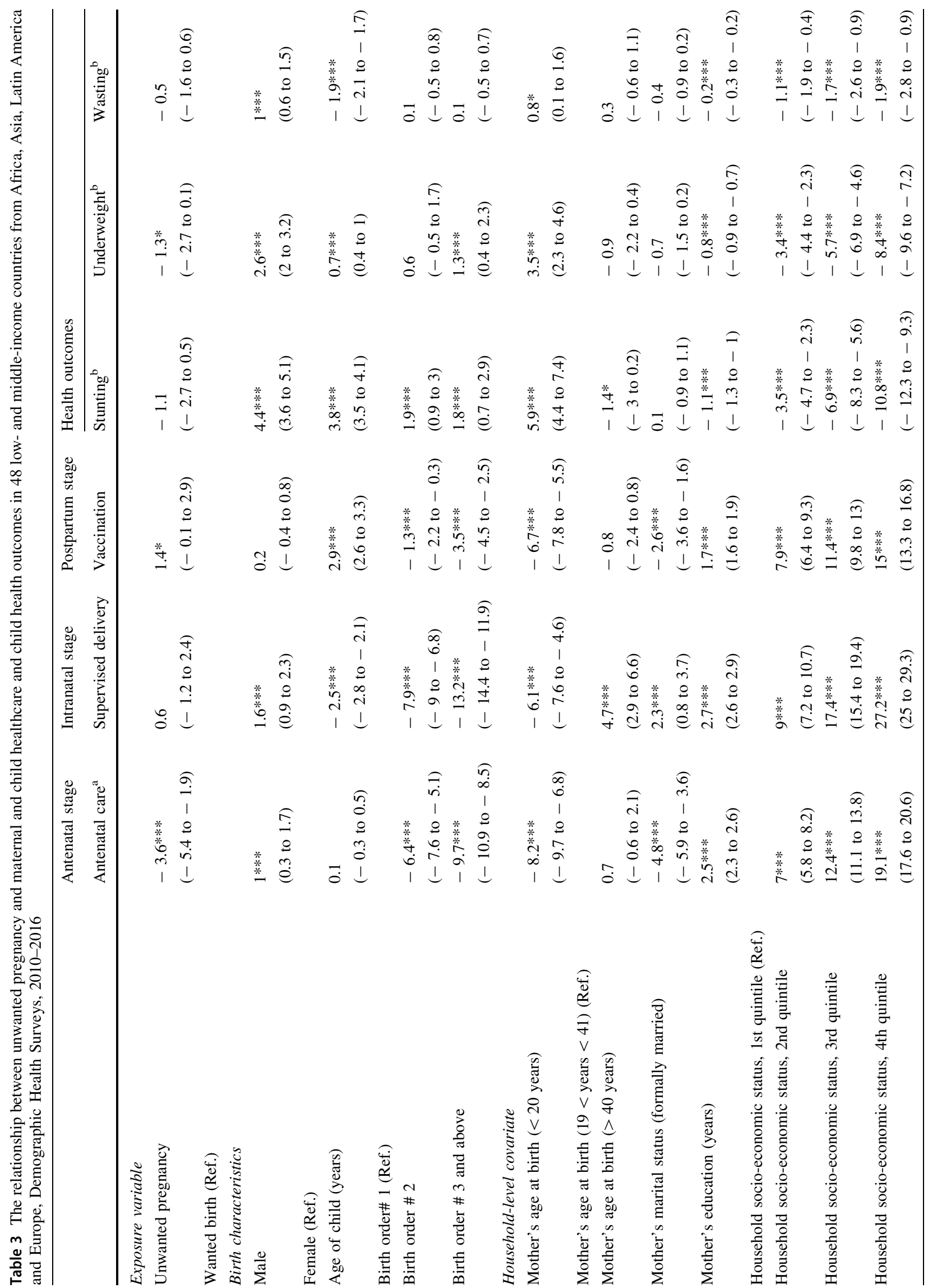




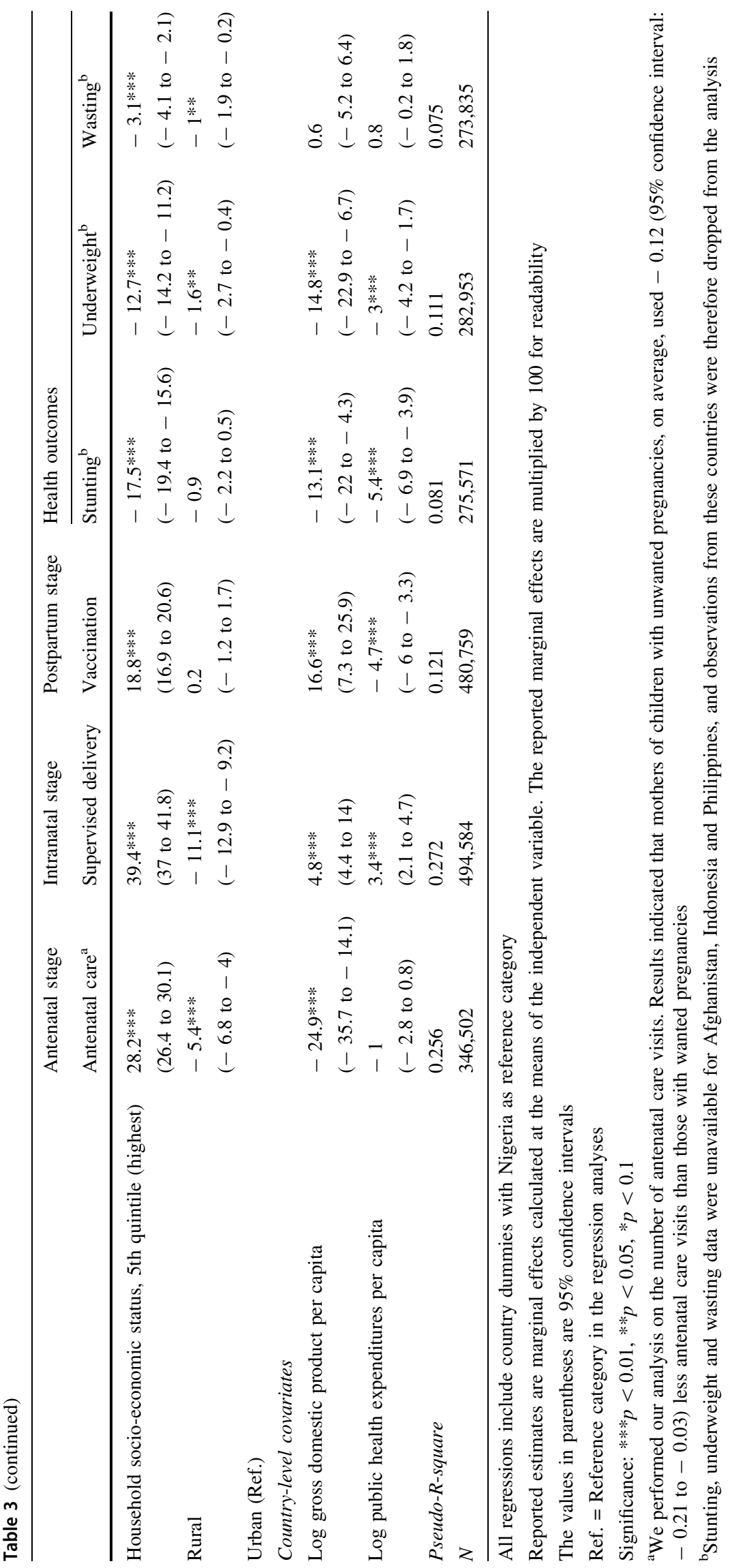


be explained by the differences in the study population and time frame of the studies.

The key strength of this study that enriches the current literature was the use of a large representative sample drawn from 48 LMICs countries. The large sample size enabled us to have sufficient power to assess adverse health and healthcare utilization for mother and child. Using the large pooled dataset helped us to improve the previous findings reported for a single country. There are, however, some limitations to this study. First, self-report of unwanted pregnancy is subject to criticism as it is self-reported by mothers after children are born and thus may be subject to recall bias. Second, as the DHS collects data on living children at the time of the survey, the results of this study indicated the impact of unwanted pregnancy on children who were alive at the time of the survey, discounting any effect of unwanted pregnancy on children who died prior to the survey. This may underestimate the adverse impact of unwanted pregnancy on health and healthcare utilization for mother and child if unwanted pregnancy positively associated with child mortality in LMICs. Third, some of the time-varying covariates in the study are subject to measurement error (e.g. the household's SES) because they are reported at the time of interview and assigned to all prior births. Fourth, other factors such as family and social environments and health system characteristics may also influence maternal and child health and healthcare, but were excluded from our analyses because of lack of information in DHS. Fifth, because of the cross-sectional design of the study, it was not possible to establish temporality; thus, the evidence for causality can only be suggested. Finally, with the use of sampling weights in the analysis, the results of this study are generalizable only to the 48 LMICs included in our analyses and further extrapolation of the findings to other countries should be done with caution.

\section{Conclusion}

Although we found an adverse impact of unwanted pregnancy on antennal care, our result did not suggest any association between unwanted pregnancy on supervised delivery, childhood vaccination and nutritional status of children. Our results indicated that birth characteristics, household-level determinants and country-level characteristics seem to be more closely related to maternal and child healthcare utilization as well as nutritional status of children than whether the pregnancy was wanted or not in LMICs.

Acknowledgements We gratefully acknowledge MEASURE DHS for their permission to use the Demographic Health Surveys. We would like to thank Sandie Du for her research assistance. We also would like to thank three anonymous reviewers for their helpful comments, which substantially improved the manuscript.

Funding The authors did not receive any funding for this study.

\section{Compliance with ethical standards}

Conflict of interest The authors declare no conflict of interest.

Ethical approval This article does not contain any studies with human participants performed by any of the authors.

Open Access This article is licensed under a Creative Commons Attribution 4.0 International License, which permits use, sharing, adaptation, distribution and reproduction in any medium or format, as long as you give appropriate credit to the original author(s) and the source, provide a link to the Creative Commons licence, and indicate if changes were made. The images or other third party material in this article are included in the article's Creative Commons licence, unless indicated otherwise in a credit line to the material. If material is not included in the article's Creative Commons licence and your intended use is not permitted by statutory regulation or exceeds the permitted use, you will need to obtain permission directly from the copyright holder. To view a copy of this licence, visit http://creativecommons. org/licenses/by/4.0/.

\section{References}

Amo-Adjei J, Anamaale Tuoyire D (2016) Effects of planned, mistimed and unwanted pregnancies on the use of prenatal health services in sub-Saharan Africa: a multicountry analysis of Demographic and Health Survey data. Trop Med Int Health 21:1552-1561. https://doi.org/10.1111/tmi.12788

Barrick L, Koenig MA (2008) Pregnancy intention and antenatal care use in two rural north Indian States. World Health Popul 10:21-37

Baschieri A, Machiyama K, Floyd S et al (2017) Unintended childbearing and child growth in Northern Malawi. Matern Child Health J 21:467-474. https://doi.org/10.1007/s10995-016-2124-8

D'Angelo DV, Gilbert BC, Rochat RW et al (2004) Differences between mistimed and unwanted pregnancies among women who have live births. Perspect Sex Reprod Health 36:192-197. https://doi.org/10.1363/psrh.36.192.04

De Onis M (2006) WHO child growth standards: length/height-forage, weight-for-age, weight-for-length, weight-for-height and body mass index-for-age: methods and development. World Health Organization, Geneva

Demographic and Health Survey (1996) Sampling manual. DHS-III, Calverton

Demographic and Health Survey (2006) Demographic and health survey interviewer's manual. Demographic and Health Survey, Calverton

Donohue JJ III, Levitt SD (2001) The impact of legalized abortion on crime. Q J Econ 116:379-420

Echaiz J, Blas M, Kancherla V (2018) Unintended pregnancy and its impact on childhood rotavirus immunization in Peru. Rev Panam Salud Publica 42:e96. https://doi.org/10.26633/RPSP.2018.96

Filmer D, Pritchett LH (2001) Estimating wealth effects without expenditure data - or tears: an application to educational enrollments in states of India. Demography 38:115-132. https://doi. org/10.1353/dem.2001.0003 
Gipson JD, Koenig MA, Hindin MJ (2008) The effects of unintended pregnancy on infant, child, and parental health: a review of the literature. Stud Fam Plann 39:18-38. https://doi.org/10.1111/j. 1728-4465.2008.00148.x

Haffejee F, O'Connor L, Govender N et al (2018) Factors associated with unintended pregnancy among women attending a public health facility in KwaZulu-Natal, South Africa. S Afr Fam Pract 60:79-83. https://doi.org/10.1080/20786190.2017.1396790

Hajizadeh M (2019) Decomposing socioeconomic inequality in child vaccination in the Gambia, the Kyrgyz Republic and Namibia. Vaccine 37:6609-6616. https://doi.org/10.1016/j.vaccine.2019. 09.054

Hajizadeh M, Heymann J, Strumpf E et al (2015) Paid maternity leave and childhood vaccination uptake: longitudinal evidence from 20 low-and-middle-income countries. Soc Sci Med 140:104-117. https://doi.org/10.1016/j.socscimed.2015.07.008

Hall JA, Benton L, Copas A, Stephenson J (2017) Pregnancy intention and pregnancy outcome: systematic review and metaanalysis. Matern Child Health J 21:670-704. https://doi.org/10. 1007/s10995-016-2237-0

Hoddinott J, Alderman H, Behrman JR et al (2013) The economic rationale for investing in stunting reduction. Matern Child Nutr 9(Suppl 2):69-82. https://doi.org/10.1111/mcn.12080

ICF International (2012) Demographic and health survey sampling and household listing manual. MEASURE DHS, ICF International, Calverton

Ikamari L, Izugbara C, Ochako R (2013) Prevalence and determinants of unintended pregnancy among women in Nairobi, Kenya. BMC Pregnancy Childbirth 13:69. https://doi.org/10.1186/14712393-13-69

Khajehpour M, Simbar M, Jannesari S et al (2013) Health status of women with intended and unintended pregnancies. Public Health 127:58-64. https://doi.org/10.1016/j.puhe.2012.08.011

Leroy JL (2011) zscore06: Stata command for the calculation of anthropometric z-scores using the 2006 WHO child growth standards. Statistical Software Components S457279, Boston College Department of Economics, Boston

Marston C, Cleland J (2003) Do unintended pregnancies carried to term lead to adverse outcomes for mother and child? An assessment in five developing countries. Popul Stud 57:77-93. https://doi.org/10.1080/0032472032000061749

Ochako R, Gichuhi W (2016) Pregnancy wantedness, frequency and timing of antenatal care visit among women of childbearing age in Kenya. Reprod Health 13:51. https://doi.org/10.1186/s12978016-0168-2

Rahman MM (2015) Is unwanted birth associated with child malnutrition in Bangladesh? Int Perspect Sex Reprod Health 41:80-88. https://doi.org/10.1363/4108015

Rahman MM, Rahman MM, Tareque MI et al (2016) Maternal pregnancy intention and professional antenatal care utilization in Bangladesh: a nationwide population-based survey. PLoS ONE 11:e0157760. https://doi.org/10.1371/journal.pone.0157760

Rutstein SO, Johnson K (2004) The DHS wealth index. DHS comparative reports no. 6. ORC Macro, MEASURE DHS

Rutstein SO, Rojas G (2006) Guide to DHS statistics: demographic and health surveys methodology. U.S. Agency for International Development, ORC Macro, Calverton

Schwarz EB, Smith R, Steinauer J et al (2008) Measuring the effects of unintended pregnancy on women's quality of life. Contraception 78:204-210. https://doi.org/10.1016/j.contraception. 2008.04.120

Sedgh G, Singh S, Hussain R (2014) Intended and unintended pregnancies worldwide in 2012 and recent trends. Stud Fam Plann 45:301-314. https://doi.org/10.1111/j.1728-4465.2014. 00393.x
Singh S, Darroch JE (2000) Adolescent pregnancy and childbearing: levels and trends in developed countries. Fam Plann Perspect 32:14-23. https://doi.org/10.2307/2648144

Singh S, Moore A, Bankole A et al (2006) Unintended pregnancy and induced abortion in Uganda: causes and consequences. Guttmacher Institute, New York

Singh S, Sedgh G, Hussain R (2010) Unintended pregnancy: worldwide levels, trends, and outcomes. Stud Fam Plann 41:241-250. https://doi.org/10.1111/j.1728-4465.2010.00250.x

Singh A, Singh A, Thapa S (2015) Adverse consequences of unintended pregnancy for maternal and child health in Nepal. Asia Pac J Public Heal 27:NP1481-NP1491. https://doi.org/10. $1177 / 1010539513498769$

Singh A, Upadhyay AK, Singh A, Kumar K (2017) The association between unintended births and poor child development in india: evidence from a longitudinal study. Stud Fam Plann 48:55-71. https://doi.org/10.1111/sifp.12017

Singh S, Remez L, Sedgh G et al (2018) Abortion worldwide 2017: uneven progress and unequal access. Guttmacher Institute, New York

Sonfield A, Kost K (2015) Public costs from unintended pregnancies and the role of public insurance programs in paying for pregnancy-related care: national and state estimates for 2010 . Guttmacher Institute, New York

The DHS Program (2019) DHS overview. http://dhsprogram.com/ What-We-Do/Survey-Types/DHS.cfm. Accessed 17 June 2019

UN DESA (2020) World population prospects. https://population.un. org/wpp/Download/Standard/Population/. Accessed 6 Jan 2020

Wado YD, Afework MF, Hindin MJ (2013) Unintended pregnancies and the use of maternal health services in southwestern Ethiopia. BMC Int Health Hum Rights 13:36. https://doi.org/10.1186/ 1472-698X-13-36

World Bank (2019) World development indicators database. Washington, DC. http://databank.worldbank.org/data/home.aspx. Accessed 6 June 2019

World Health Organization (2004) Making pregnancy safer: why is this issue important? Fact sheet 276. World Health Organization, Geneva

World Health Organization (2006a) Provision of effective antenatal care: integrated management of pregnancy and childbirth (IMPAC). https://www.who.int/reproductivehealth/publications/ maternal_perinatal_health/effective_antenatal_care.pdf. Accessed 4 Mar 2020

World Health Organization (2006b) WHO child growth standards: length/height for age, weight-for-age, weight-for-length, weightfor-height and body mass index-for-age, methods and development. World Health Organization, Geneva

World Health Organization (2012) Safe abortion: technical and policy guidance for health systems Second edition technical and policy guidance for health systems, 2nd edn. World Health Organization, Geneva

World Health Organization (2019) Table 2: summary of WHO position papers-recommended routine immunizations for children. http://www.who.int/immunization/policy/Immunization_ routine_table2.pdf?ua=1. Accessed 6 June 2019

Yazdkhasti M, Pourreza A, Pirak A, Abdi F (2015) Unintended pregnancy and its adverse social and economic consequences on health system: a narrative review article. Iran J Public Health $44: 12-21$

Publisher's Note Springer Nature remains neutral with regard to jurisdictional claims in published maps and institutional affiliations. 